\title{
Explicit Design of Innovation Performance Metrics by Using Analytic Hierarchy Process Expansion
}

\author{
Song-Kyoo Kim \\ W. Sycip Graduate School of Business, Asian Institute of Management, 123 Paseo de Roxas, 1229 Makati, Philippines \\ Correspondence should be addressed to Song-Kyoo Kim; skim@aim.edu
}

Received 4 February 2014; Accepted 27 March 2014; Published 14 May 2014

Academic Editor: Michael M. Tom

Copyright (C) 2014 Song-Kyoo Kim. This is an open access article distributed under the Creative Commons Attribution License, which permits unrestricted use, distribution, and reproduction in any medium, provided the original work is properly cited.

\begin{abstract}
The paper presents the explicit and objective measurement method for innovation performances by using the extensive version of Analytic Hierarchy Process (AHP). A hierarchical framework is constructed for the innovation performance criteria and giving the guideline for innovation performance of companies. By applying AHP Expansion framework, the innovation performance measurement factors can be prioritized and descending-order rank list of the performance factors can be made in order to select the best strategies to improve the innovativeness of companies. This new framework of innovation measurement is targeted for implementation at the actual analysis for innovation competitiveness of companies and expected to provide the milestones of measuring the innovation more effectively.
\end{abstract}

\section{Introduction}

Current corporate world understands that innovation is more evident and creating business value is the purpose of innovation. Global companies are focused on making innovation more understandable to be able to manage and improve their business because the companies are facing high competition because of endless globalization. The value of innovation can be considered in many different forms. Regardless of company size, modern companies are driven to survive and to grow. Finding the solution for the rapidly changing market which is to innovative effectively is the way to survive. But most of companies fail to sustain their innovativeness because they miss the critical parts of the equation: metrics and measurements. Innovation uncertainty principle means that the procedure to measure innovation of the company may interrupt the innovation process because innovation by itself involves venture for the unknown factors, and the company could make the unknown factors harder to realize or recognize if the company tries to pin these unknowns down too fast [1].

The criteria to measure the innovation are the critical issue and several researches [2-7] suggest the framework of innovation metric criteria. Innovation can be viewed as having three distinct approaches. There are many alternatives for choosing the innovation metrics but three distinct approaches are appropriate approaches [2-5]. All three components should be measured thoroughly. The practical ways of measuring innovation differ highly from the metrics suggested by theory, through highly unbalanced and seemingly random metrics. There is a need for a framework on how to select which innovation metrics that an organization should use. The aim of creating this framework is to show that despite small changes of the metrics in use, improvements could be achieved fairly easily. Since the innovation does not physically exist and is not shown as clear numbers, it is very hard to determine the measuring criteria. Even current researches [5] can only suggest the survey from CEO (Chief Executive Officer) level persons in the companies which launch the innovative products or services. In fact, companies launching innovative products does not mean that the companies are innovative by themselves. In other words, the innovation performance criteria for measurement can be listed but there are no indications for which criteria are important than other criteria.

The Analytic Hierarchy Process (AHP) is a structured technique for analyzing complex decisions [8-10]. The 
axiomatic foundation of the AHP (Analytic Hierarchy Process) carefully delimits the scope of the problem environment although it can be applied widely [11]. AHP was developed by Thomas L. Saaty in the 1970s based on his mathematical and psychological knowledge and is also referred to as the Saaty method. The method is mathematically simple but the very practical tool. The AHP can transform oneon-one comparison values into ratio-scale weighted values that are the combination between linear additives with the related alternatives. The core of AHP is building up a matrix expressing the relative values of the attribute set based on the pairwise comparison. There are the homogeneity axiom states that the elements being compared should not differ by too much in the property being compared [12]. For instance, there are three criteria (or attributes) to buy one product within three alternatives (products $X, Y$, and $Z$ ): delivery time $(D)$, quality $(Q)$, and cost $(C)$. And these criteria have the related importance to select one within three candidate products. First, you need to decide whether $D$ is much more important (or more important or less important) than $Q$ and whether $Q$ is much more important (or more important or less important) than $C$ and so on. Each of these comparison values is assigned a number of discrete scales [8]. One of reasonable assumptions is that if $D$ is absolutely more important than $C$ and is rated as 9 , it means that $C$ must be absolutely less important than $D$ and its value should be $1 / 9$. The calculation of the matrix that is built based on the relative weights is the next step. Eigenvector is the vector that contains the list for the weight factors of criteria. The next step is the pairwise comparison between products $(X-Y, X-Z$, and $Y-Z)$ based on each criteria $(D, Q$, and $C)$ and calculating the list for the weight factors of products $(X, Y$, and $Z)$ for each criteria ( 3 criteria for this example). Once the full sets are calculated, the eigenvalue of each product can be calculated by summing the values on each criterion. For instance, the eigenvalue of product $X$ is summing the value of $\mathrm{X}$ in delivery criterion $(D)$, the value of $X$ in cost criterion $(C)$, and the value of $X$ in quality criterion $(Q)$. As for the further step, the consistency ratio $(\mathrm{CR})$ should be calculated to measure how much values are biased (or fair). If the consistency ratio highly exceeds more than 0.1, the values cannot be trusted (i.e., biased).

On the top of AHP, there is AHP Expansion [13] that is for determining the innovation performance criteria and providing the general guidelines to evaluate the relationship within criteria. It gives enough flexibility to apply for analyzing the innovation performance measure and guidelines how to handle the real situations. This innovative measuring methodology will provide the more suitable analysis to determine which factors are more important than others for managing the innovation. Since, AHP Expansion framework is based on the classical AHP method, all of advantages of the classical AHP could be counted as the advantages of the proposed method. As for the advantages [14], the proposed method can be applied not only to quantitative measure but also to qualitative measure. It is easy to use and can check the consistency of data able to remove the potential inconsistencies in advance. Because of using pairwise comparison, it has triggered to develop many other MCDM (Multiple Criteria Decision Making) methods and
AHP (Expansion) is the mother of modern MCDM methods. As for the disadvantages [15], AHP (Expansion) could reverse the ranking of factors when the matrix contains identical values. In case of a simple MDCM case, all units (e.g., dollars) of elements can be determined as the same units but many real-world MDCM situations may require multiple units for the different dimensions. However, AHP is one of most reliable and widely accepted MCDM methods $[15,16]$. That is the reason why AHP is applied for measuring innovation performance as AHP Expansion framework.

\section{Priorities of Innovation Performance Measure}

The innovation performance metrics have been proposed [1] and applied by various consulting companies [2-7]. There are three distinct but related components Input-related, Processrelated, and Output-related metrics adapted from [17]. Each component contains several subcriteria for evaluating the performance.

Input-Related Measures

$I_{1}$ : financial resources dedicated to innovation,

$I_{2}$ : human resources focused on innovation,

$I_{3}$ : protected resources for noncore innovations,

$I_{4}$ : senior management time invested in new growth innovation,

$I_{5}$ : IP (intellectual property; patents) activities.

Process-Related Measures

$P_{1}$ : process speed,

$P_{2}$ : diverse of idea-generation process,

$P_{3}$ : innovation portfolio balance,

$P_{4}$ : gap between actions and plans,

$P_{5}$ : distinct process, tools, and metrics for different types of opportunities.

Output-Related Measure

$\mathrm{O}_{1}$ : number of new products or service launched,

$\mathrm{O}_{2}$ : portion of revenue in core categories from new products,

$\mathrm{O}_{3}$ : portion of profit from new customers (or occasions),

$\mathrm{O}_{4}$ : portion of profit from new categories,

$\mathrm{O}_{5}$ : return of investment (ROI) by innovation.

Even though the above criteria are very useful, they do not have any indicator which one is more important than others. The criteria should be categorized and prioritized to give the better indications to determine the innovation performance of the company or organization. AHP Expansion is applied to determine the priority of the innovation performance factors. 
All values of innovation performance are based on the ratio and the ranges of the values between 0 and 1 . These innovation criteria become the weight factor when the companies are analyzed for their innovation performance.

\section{Overview of Analytic Hierarchy Process Expansion}

The AHP Expansion [13] is the extend method that gives more flexible usage of the classical AHP method. It can have multiple depths of criteria instead of one depth to determine the weight factors for priority. The following formulas in this session are adapted from the previous research [13]. Let the matrix $\mathbb{C}$ be the relationship matrix within criteria. The AHP verbal scale ranges from 1 to 7 (or 9) or about an order of magnitude:

$$
\mathbb{C}=\left[\begin{array}{ccccc}
c_{1,1} & c_{1,2} & \ldots & \ldots & c_{1, n} \\
c_{2,1} & c_{2,2} & \ldots & \ldots & c_{2, n} \\
\vdots & \vdots & \vdots & \vdots & \vdots \\
\vdots & \vdots & \vdots & \vdots & \vdots \\
c_{n, 1} & c_{n, 2} & \ldots & \ldots & c_{n, n}
\end{array}\right]
$$

To get the normalized scale for each criterion, the matrix $\mathbb{C}$ is transformed as

$$
\widehat{\mathbb{C}}=\left[\begin{array}{ccccc}
\widehat{c}_{1,1} & \widehat{c}_{1,2} & \ldots & \ldots & \widehat{c}_{1, n} \\
\widehat{c}_{2,1} & \widehat{c}_{2,2} & \ldots & \ldots & \widehat{c}_{2, n} \\
\vdots & \vdots & \vdots & \vdots & \vdots \\
\vdots & \vdots & \vdots & \vdots & \vdots \\
\widehat{c}_{n, 1} & \widehat{c}_{n, 2} & \ldots & \ldots & \widehat{c}_{n, n}
\end{array}\right],
$$

where

$$
\widehat{c}_{i, j}=\frac{c_{i, j}}{\sum_{k=1}^{n} c_{k, j}}
$$

Let $\widehat{W}$ be the diagonal matrix that contains the weight factors for each criterion. By using the elementary matrix algebra, the solution can be found as follow:

$$
\widehat{\mathbb{W}}=\frac{1}{n} \cdot \widehat{\mathbb{C}} \cdot \mathbb{q}_{[n, 1]}=\left[\begin{array}{c}
\widehat{w}_{1} \\
\widehat{w}_{2} \\
\vdots \\
\widehat{w}_{n-1} \\
\widehat{w}_{n}
\end{array}\right],
$$

where

$$
\widehat{w}_{k}=\frac{1}{n} \cdot \sum_{j=1}^{n} c_{k, j}, \quad k=1, \ldots, n .
$$

Let $\mathbb{S}^{i}$ be the matrix for the second degree criteria for the main criteria $i$ and same as alternatives in the classical AHP. But the second degree criterion is more flexible than alternatives in the classical AHP. Technically, alternatives are the special case of the second degree criteria in AHP Expansion. Since the number of the criteria is determined as $n$, the range of $i$ is $1, \ldots, n$ and the number of second degree criteria in each $i$ criteria is $m_{i}$ :

$$
\mathbb{S}^{i}=\left[\begin{array}{ccccc}
s_{1,1}^{i} & s_{1,2}^{i} & \ldots & \ldots & s_{1, m_{i}}^{i} \\
s_{2,1}^{i} & s_{2,2}^{i} & \ldots & \ldots & s_{2, m_{i}}^{i} \\
\vdots & \vdots & \vdots & \vdots & \vdots \\
\vdots & \vdots & \vdots & \vdots & \vdots \\
s_{m_{i}, 1}^{i} & s_{m_{i}, 2}^{i} & \ldots & \ldots & s_{m_{i}, m_{i}}^{i}
\end{array}\right], \quad i=1, \ldots, n .
$$

To get the normalized scale for each factor in the category $i$, the matrix $\mathbb{S}^{i}$ is transformed as

$$
\widehat{\mathbb{S}}^{i}=\left[\begin{array}{ccccc}
\hat{s}_{1,1}^{i} & \hat{s}_{1,2}^{i} & \ldots & \ldots & \widehat{s}_{1, m_{i}}^{i} \\
\widehat{s}_{2,1}^{i} & \hat{s}_{2,2}^{i} & \ldots & \ldots & \widehat{s}_{2, m_{i}}^{i} \\
\vdots & \vdots & \vdots & \vdots & \vdots \\
\vdots & \vdots & \vdots & \vdots & \vdots \\
\hat{s}_{m_{i}, 1}^{i} & \hat{s}_{m_{i}, 2}^{i} & \ldots & \ldots & \widehat{s}_{m_{i}, m_{i}}^{i}
\end{array}\right]
$$

where

$$
\widehat{s}_{j, k}^{i}=\frac{s_{j, k}^{i}}{\sum_{l=1}^{m_{i}} s_{l, k}^{i}} ; \quad i=1, \ldots, n ; j=1, \ldots, m_{i} .
$$

Let $\widehat{\mathbb{F}}_{i}$ be the diagonal matrix that contains the weighted values for each alternative choice within the criteria $i$. By using the elementary matrix algebra, the solution can be found as follow:

$$
\widehat{\mathbb{F}}_{i}=\frac{1}{m_{i}} \cdot \widehat{\mathbb{S}}^{i} \cdot \rrbracket_{[n, 1]}=\left[\begin{array}{c}
\widehat{f}_{1}^{i} \\
\widehat{f}_{2}^{i} \\
\vdots \\
\widehat{f}_{n-1}^{i} \\
\widehat{f}_{m_{i}}^{i}
\end{array}\right], \quad i=1, \ldots, n,
$$

where

$$
\widehat{f}_{k}^{i}=\frac{1}{m_{i}} \cdot \sum_{j=1}^{m_{i}} \hat{s}_{k, j}, \quad i=1, \ldots, n .
$$

Evaluation matrix is

$$
\Phi_{k}=\widehat{w}_{k} \cdot \widehat{\mathbb{F}}_{k}, \quad k=1, \ldots, n
$$




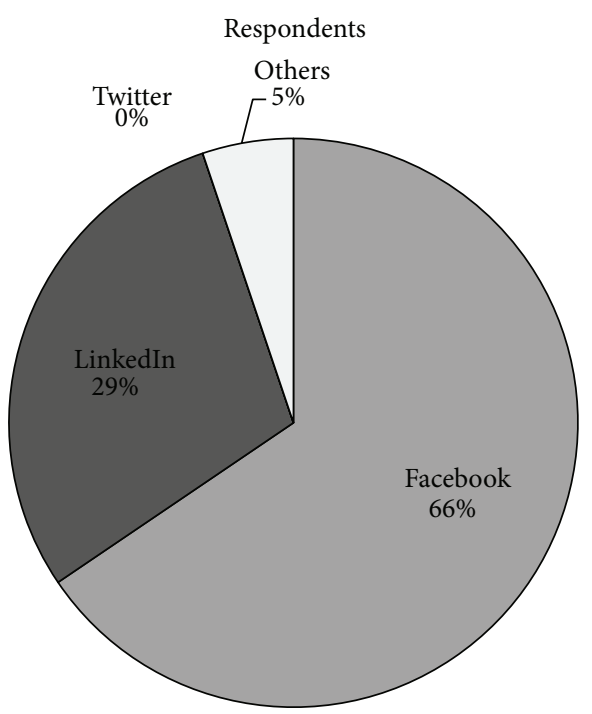

FIGURE 1: Survey respondent by SNS.

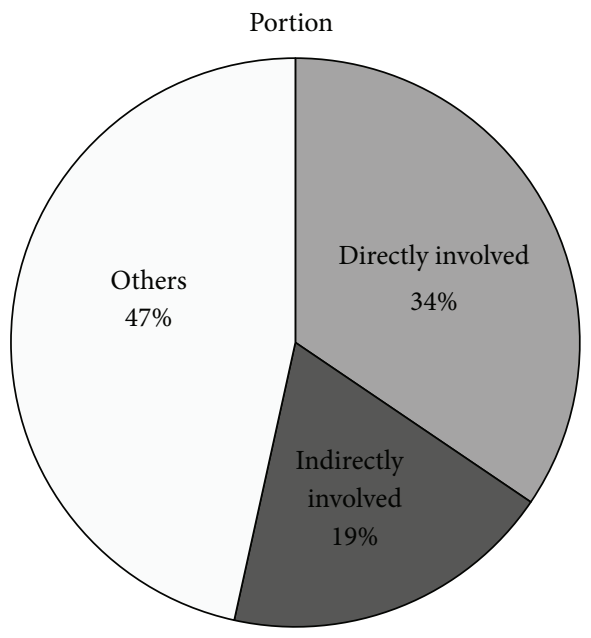

FIGURE 2: Components of survey respondents.

\section{Analysis of Innovation Performance Factors}

The survey is about understanding the relationship between the innovation factors and it has been posted around twomonth time periods on Internet and the questionnaire is shared based on SNS (Social Networking Services). SNS is a platform to build social networks and consists of a representation of each profile and a variety of additional services based on Internet (i.e., web-based services). One of benefits to use SNS for survey is giving the randomness of samples and variety of respondents [18]. In the survey, the respondents that answered questions are mostly Facebook and LinkedIn users (more than 90 percent; Figure 1).

Survey has been completed by 100 respondents and more than half respondents are involved in the innovation activities directly or indirectly (Figure 2).

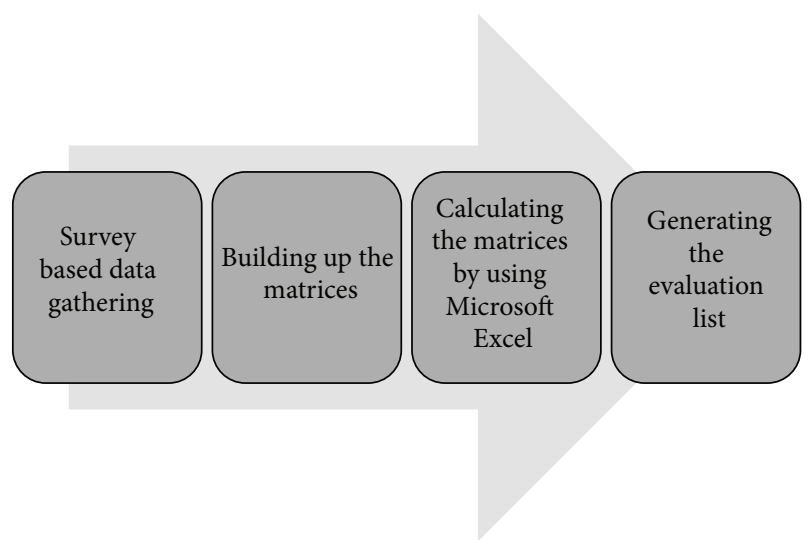

FIGURE 3: Process of categorizing innovation performance measure.

The questions are simple that ask which factor is more important than others (exactly, how much times as multiplication). AHP Expansion method can be applied based on the result of the survey. The survey is used but it is applied only in limited way to avoid the involvement of human prejustice based on their personal experiences. The process of analysis for categorizing innovation measurement factors based on AHP Expansion framework contains couple of steps after survey data gathering (Figure 3 ). The survey is designed for asking the pairwise comparisons between innovation performance measurement factors. The matrices are built up based on the online survey data by using SurveyMonkey. The AHP Expansion framework shows how to calculate each matrix analytically. Each matrix can be solved manually (by following session 3) or it can be easy to implement on computer tools because the matrix calculation is based on the linear algebra and the size of the matrices are small. It does not require the high performance computers and any computer even smartphones can handle the matrix calculation for this research. MS-Excel is applied as the matrix calculation tool for this project because it can also provide the related graphs and charts (Figure 4).

According to AHP Expansion, the survey results are mapped in the relationship matrix

$$
\mathbb{C}=\left[\begin{array}{lll}
1.00 & 0.51 & 0.47 \\
1.97 & 1.00 & 0.53 \\
2.21 & 1.90 & 1.00
\end{array}\right],
$$

and the normalized relation matrix $\widehat{\mathbb{C}}$ is determined from (1)(3)

$$
\widehat{\mathbb{C}}=\left[\begin{array}{lll}
0.20 & 0.15 & 0.24 \\
0.39 & 0.29 & 0.26 \\
0.42 & 0.56 & 0.50
\end{array}\right] \text {. }
$$

From (4)-(5) and (12)-(13), the weight factors for each category of innovation can be solved by the elementary matrix algebra:

$$
\widehat{\mathbb{W}}=\frac{1}{3} \cdot \widehat{\mathbb{C}} \cdot\left[\begin{array}{l}
1 \\
1 \\
1
\end{array}\right]=\left[\begin{array}{l}
0.19 \\
0.32 \\
0.49
\end{array}\right] .
$$


TABLE 1: Average random consistency.

\begin{tabular}{lcccccc}
\hline Size of matrix & 2 & 3 & 4 & 5 & 6 & 7 \\
\hline Random consistency & 0.00 & 0.58 & 0.90 & 1.12 & 1.24 & 1.32 \\
\hline
\end{tabular}

Based on the analysis, the performance factors in OutputRelated category (around 50 percent) are more important than the factors in other categories to measure the innovativeness of the company. To estimate the consistency ratio,

$$
\begin{gathered}
\mathbb{C} \cdot \widehat{\mathbb{W}}=\lambda_{\max } \cdot \widehat{\mathbb{W}} \\
{\left[\begin{array}{lll}
1.00 & 0.51 & 0.47 \\
1.97 & 1.00 & 0.53 \\
2.21 & 1.90 & 1.00
\end{array}\right] \cdot\left[\begin{array}{l}
0.19 \\
0.32 \\
0.49
\end{array}\right]=\lambda_{\max } \cdot\left[\begin{array}{l}
0.19 \\
0.32 \\
0.49
\end{array}\right],} \\
{\left[\begin{array}{l}
0.59 \\
0.96 \\
1.50
\end{array}\right]=\lambda_{\max } \cdot\left[\begin{array}{l}
0.19 \\
0.32 \\
0.49
\end{array}\right] .}
\end{gathered}
$$

Dividing all the elements of the metrics by their respective priority element and computing the average of the values,

$$
-\lambda_{\max }=\frac{3.02+3.04+3.05}{3}=3.04 \text {. }
$$

From (16), the consistency index (CI) can be found:

$$
\mathrm{CI}=\frac{\lambda_{\max }-n}{n-1}=\frac{3.04-3}{3-1}=0.021
$$

Select correct value of random consistency ratio RI as the 3-by-3 matrix using Table 1 [8-10] and (17).

Since average random consistency of 3-by-3 matrix is 0.58 (from Table 1), the consistency ratio (CR) of first depth of innovation criteria is

$$
C R=\frac{0.02}{0.58}=0.035<0.1
$$

As the value of $\mathrm{CR}$ is less than 0.1, the judgments are acceptable. Similarly, random consistencies of second depth matrices of innovation performance criteria (i.e., subcriteria) can be found after analyzing the performance factors.

The matrixes for the subcriteria $\mathbb{S}^{i}, i=1, \ldots, 3$ are as follows from (6):

$$
\begin{aligned}
& \mathbb{S}^{1}=\left[\begin{array}{lllll}
1.00 & 0.52 & 0.57 & 0.41 & 0.40 \\
1.94 & 1.00 & 0.61 & 0.50 & 0.51 \\
1.76 & 1.65 & 1.00 & 0.45 & 0.47 \\
2.46 & 1.99 & 2.22 & 1.00 & 0.45 \\
2.52 & 1.97 & 2.14 & 2.23 & 1.00
\end{array}\right], \\
& \mathbb{S}^{2}=\left[\begin{array}{lllll}
1.00 & 0.33 & 0.41 & 0.46 & 0.34 \\
3.07 & 1.00 & 0.55 & 0.56 & 0.54 \\
2.44 & 1.82 & 1.00 & 0.59 & 0.53 \\
2.19 & 1.78 & 1.70 & 1.00 & 0.43 \\
2.96 & 1.85 & 1.88 & 2.33 & 1.00
\end{array}\right], \\
& \mathbb{S}^{3}=\left[\begin{array}{lllll}
1.00 & 0.35 & 0.32 & 0.36 & 0.35 \\
0.83 & 1.00 & 0.38 & 0.43 & 0.46 \\
3.13 & 2.63 & 1.00 & 0.48 & 0.48 \\
2.75 & 2.33 & 2.08 & 1.00 & 0.56 \\
2.83 & 2.17 & 2.08 & 1.78 & 1.00
\end{array}\right] .
\end{aligned}
$$

From (19) and (6)-(8), the matrixes that contain the normalized scale for each factor can be found as

$$
\begin{aligned}
\widehat{\mathbb{S}}^{1} & =\left[\begin{array}{lllll}
0.10 & 0.17 & 0.09 & 0.09 & 0.14 \\
0.20 & 0.14 & 0.09 & 0.11 & 0.18 \\
0.18 & 0.23 & 0.15 & 0.11 & 0.18 \\
0.25 & 0.28 & 0.34 & 0.22 & 0.16 \\
0.26 & 0.28 & 0.33 & 0.49 & 0.35
\end{array}\right], \\
\widehat{\mathbb{S}}^{2} & =\left[\begin{array}{lllll}
0.09 & 0.05 & 0.07 & 0.09 & 0.12 \\
0.26 & 0.15 & 0.10 & 0.11 & 0.19 \\
0.21 & 0.27 & 0.18 & 0.12 & 0.19 \\
0.19 & 0.26 & 0.31 & 0.20 & 0.15 \\
0.25 & 0.27 & 0.34 & 0.47 & 0.35
\end{array}\right], \\
\widehat{\mathbb{S}}^{3} & =\left[\begin{array}{lllll}
0.08 & 0.04 & 0.05 & 0.09 & 0.12 \\
0.23 & 0.12 & 0.06 & 0.11 & 0.16 \\
0.25 & 0.31 & 0.17 & 0.12 & 0.17 \\
0.22 & 0.28 & 0.36 & 0.25 & 0.20 \\
0.23 & 0.26 & 0.36 & 0.44 & 0.35
\end{array}\right] .
\end{aligned}
$$

From (20) and (9)-(11), the innovation performance factors can be assigned to the following values which are the weight factors that show how much important it is to indicate the innovativeness of the company:

$$
\begin{aligned}
& \Phi_{1}=\left[\begin{array}{l}
0.019 \\
0.028 \\
0.032 \\
0.049 \\
0.066
\end{array}\right], \quad \Phi_{2}=\left[\begin{array}{l}
0.026 \\
0.051 \\
0.061 \\
0.070 \\
0.106
\end{array}\right], \\
& \Phi_{3}=\left[\begin{array}{l}
0.038 \\
0.066 \\
0.100 \\
0.127 \\
0.160
\end{array}\right] .
\end{aligned}
$$

Based on the analysis from (21), Output-related performance factors are not all factors to determine the innovativeness of the company, what most of the current consulting firms do for measuring the innovation of companies. Processrelated factors such as distinct process dedicated for innovation are also important (Figure 4).

\section{Conclusion and Further Study}

Table 2 shows the ranking list of innovation performance measurement factors. As you guess, it may be obvious that Output-related measurement factors are more important than other related factors. Return of innovation investment $\mathrm{O}_{5}$ and creating the new category of the market $\mathrm{O}_{4}$ are the critical factors to judge the innovativeness of the company. In addition, companies may be considered as more innovative if distinct innovation process $P_{5}$ is the part of their development cycle with the traditional process. Recently, more companies are interested in the dedicated process that is targeted to generate new ideas and technologies because these different processes give more chances to think differently. DeepDive (IDEO), Lead User Research (3M), 
TABLE 2: Ranking chart of innovation performance factors.

\begin{tabular}{lccll}
\hline Rank & ID number & Category & Weight & Contents \\
\hline 1 & $O_{5}$ & Output & $15.99 \%$ & Return of investment by new technology introduced product \\
2 & $O_{4}$ & Output & $12.70 \%$ & Portion of profit from new categories \\
3 & $P_{5}$ & Process & $10.64 \%$ & Distinct process, tools, and metrics for different types of opportunities \\
4 & $O_{3}$ & Output & $9.98 \%$ & Portion of profit from new customers (or occasions) \\
5 & $P_{4}$ & Process & $6.99 \%$ & Gap between actions and plans \\
6 & $O_{2}$ & Output & $6.65 \%$ & Portion of revenue in core categories from new products \\
7 & $I_{5}$ & Input & $6.61 \%$ & IP (patents) activities \\
8 & $P_{3}$ & Process & $6.07 \%$ & Innovation portfolio balance \\
9 & $P_{2}$ & Process & $5.13 \%$ & Diverse of idea-generation process \\
10 & $I_{4}$ & Input & $4.85 \%$ & Senior management time invested in new growth innovation \\
11 & $O_{1}$ & Output & $3.83 \%$ & Number of new products or service launched \\
12 & $I_{3}$ & Input & $3.22 \%$ & Protected resources for noncore innovations \\
13 & $I_{2}$ & Input & $2.80 \%$ & Human resources focused on innovation \\
14 & $P_{l}$ & Process & $2.64 \%$ & Process speed \\
15 & $I_{1}$ & Input & $1.91 \%$ & Financial resources dedicated to innovation \\
\hline
\end{tabular}

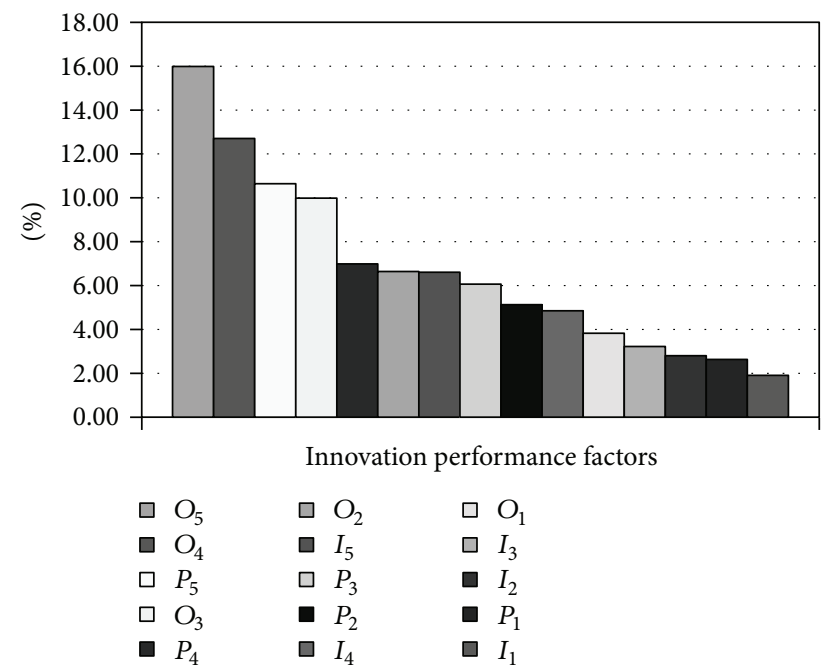

FIGURE 4: List of critical innovation performance measure.

Design's Thinking (Apple), and TRIZ (Samsung, Intel) are well-known innovation processes to deliver the new idea into the markets.

Specially, TRIZ is one of powerful and practical processes (and tools) to help people to generate new idea systematically. TRIZ (Teoriya Resheniya Izobretatelskikh Zadatch) that is also called TIPS (Theory of Inventive Problem Solving) is a methodology and model-based technology for generating innovative ideas and solutions for problem solving [19]. For instance, AMOLED (Active-Matrix Organic Light-Emitting Diode) display which is one of most advanced technologies driven by Samsung Electronics has been developed by adapting TRIZ method [20].

In addition, most of Input-related factors are not considered as important criteria. It means that it may not be effective that the company gives more financial $\left(I_{1}\right)$ or human resource $\left(I_{2}\right)$ supports to be more innovative. On the other hand, setting up and diffusion of the distinct innovation process and tools $\left(P_{5}\right)$ are more effective ways to make the company more innovative.

These innovation performance factors are the weight factors to determine the innovativeness of the company. If a company provides certain values between 0 and 1 for each factor, the values can be multiplied with the weight factors (Table 2). Once the numbers are summed, it will give one value for a company that indicates how much a company is innovative. The questions of the innovation performance cannot be asked directly because it is very hard to measure. It requires the framework that can transform clear questions to reflect on the performance factors. The values from questions should be objective, measurable, and fair enough to compare the innovativeness between companies regardless of their company size, number of employees, and their reputations. Instead of asking "how much money spent from the financial resources dedicated to innovation," it will be asked differently as the total amount of money spent dedicated to new product development and the total amount of money spent for R\&D (research and development). In other words, financial resources dedicated to innovation $\left(I_{1}\right)$ are measured based on how much the company spends from the final resources for the new products (or services) within all of $\mathrm{R} \& \mathrm{D}$ resources:

$$
\eta_{I_{1}}^{C_{1}}=\frac{\text { Financial investment dedicated for the new products [USD] }}{\text { Total amount of financial investment for R\&D [USD] }}
$$


where

$$
0 \leq \eta_{i}^{a}<1, \quad a:=\text { Target company. }
$$

The values of other performance factors $\eta_{i}^{a}$ can be calculated similarly but this requires the correct question set that is transformed into the innovation performance measure. Once all values are calculated for a certain company, the innovation indicator of the company can be provided by simple matrix multiplication. Furthermore, design of the questionnaire and the framework for transformation of measuring innovation performance and applying this method to the companies for doing an actual measuring of the innovativeness are the next topics of the further studies.

\section{Conflict of Interests}

The author declares that there is no conflict of interests regarding the publication of this paper.

\section{References}

[1] R. G. Eccles, "The performance measurement manifesto," Harvard Business Review, vol. 69, no. 1, pp. 131-137, 1991.

[2] J. P. Andrew, H. L. Sirkin, K. Haanaes, and D. C. Michael, Measuring Innovation 2006, Boston Consulting Group, Boston, NY, USA, 2006, http://www.bcg.com.

[3] J. P. Andrew, H. L. Sirkin, K. Haanaes, and D. C. Michael, Measuring Innovation 2007, Boston Consulting Group, Boston, NY, USA, 2007, http://www.bcg.com.

[4] J. P. Andrew, H. L. Sirkin, K. Haanaes, and D. C. Michael, Measuring Innovation 2008, Boston Consulting Group, Boston, NY, USA, 2008, http://www.bcg.com.

[5] J. P. Andrew, H. L. Sirkin, K. Haanaes, and D. C. Michael, Measuring Innovation 2009, Boston Consulting Group, Boston, NY, USA, 2010, http://www.bcg.com.

[6] L. Morris, "Innovation metrics: the innovation process and how to measure It," An InnovationLabs White Paper, InnovationLab LLC, 2008.

[7] G. Manoochehri, "Measuring innovation: challenges and best practices," California Journal of Operations Management, vol. 8, no. 1, pp. 66-73, 2010.

[8] T. L. Saaty, The Analytic Hierarchy Process, McGraw-Hill, New York, NY, USA, 1980.

[9] T. L. Saaty, "Axiomatic foundation of the analytic hierarchy process," Management Science, vol. 32, no. 7, pp. 841-855, 1986.

[10] T. L. Saaty, "How to make a decision: the analytic hierarchy process," Interfaces, vol. 24, pp. 19-43, 1994.

[11] E. H. Forman and S. I. Gass, "The analytic hierarchy processan exposition," Operations Research, vol. 49, no. 4, pp. 469-486, 2001.

[12] N. Bhushan and K. Rai, Strategic Decision Making: Applying the Analytic Hierarchy Process, Springer, London, UK, 2004.

[13] S.-K. Kim, "Analytic hierarchy process expansion for innovation performance measurement framework," Journal of Engineering, vol. 2013, Article ID 632845, 6 pages, 2013.

[14] A. Ghoshal, "Application of AHP to APR decisions," BPTrends, 9 pages, 2013.

[15] E. Triantaphyllou and S. H. Mann, "Using the Analytic Hierarchy Process for decision making in engineering applications:

some challenges," International Journal of Industrial Engineering: Applications and Practice, vol. 2, no. 1, pp. 35-44, 1995.

[16] K. M. A. Al-Harbi, "Application of the AHP in project management," International Journal of Project Management, vol. 19, pp. 19-27, 2001.

[17] S. Anthony, The Innovator's Guide to Growth, Harvard Business Press, Boston, NY, USA, 2008.

[18] D. Boyd and N. Ellison, "Social network sites: definition, history, and scholarship," Journal of Computer-Mediated Communication, vol. 13, no. 1, article 11, 2007.

[19] G. Altshuller, And Suddenly the Inventor Appeared: TRIZ, the Theory of Inventive Problem Solving, Technical Innovation Center, Worcester, MA, USA, 1996.

[20] H. Shaughnessy, "How samsung became such a formidable competitor," Forbes (Online), 2013, http://onforb.es/Z1LR5q. 


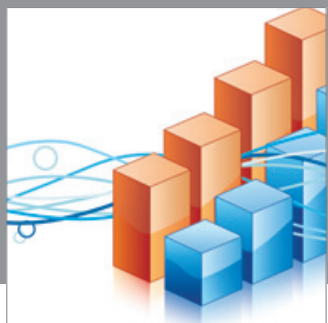

Advances in

Operations Research

mansans

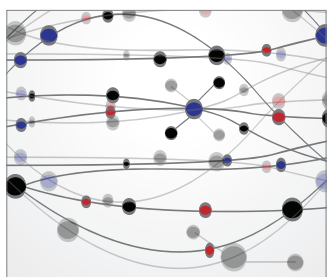

The Scientific World Journal
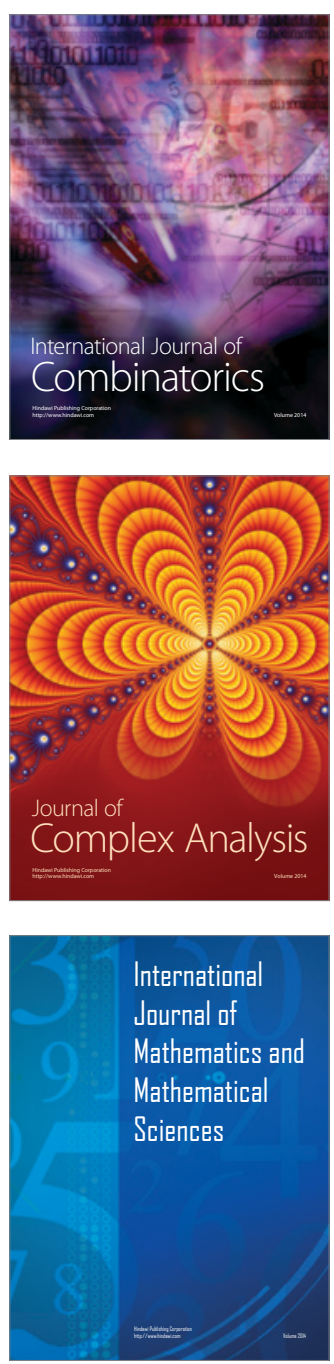
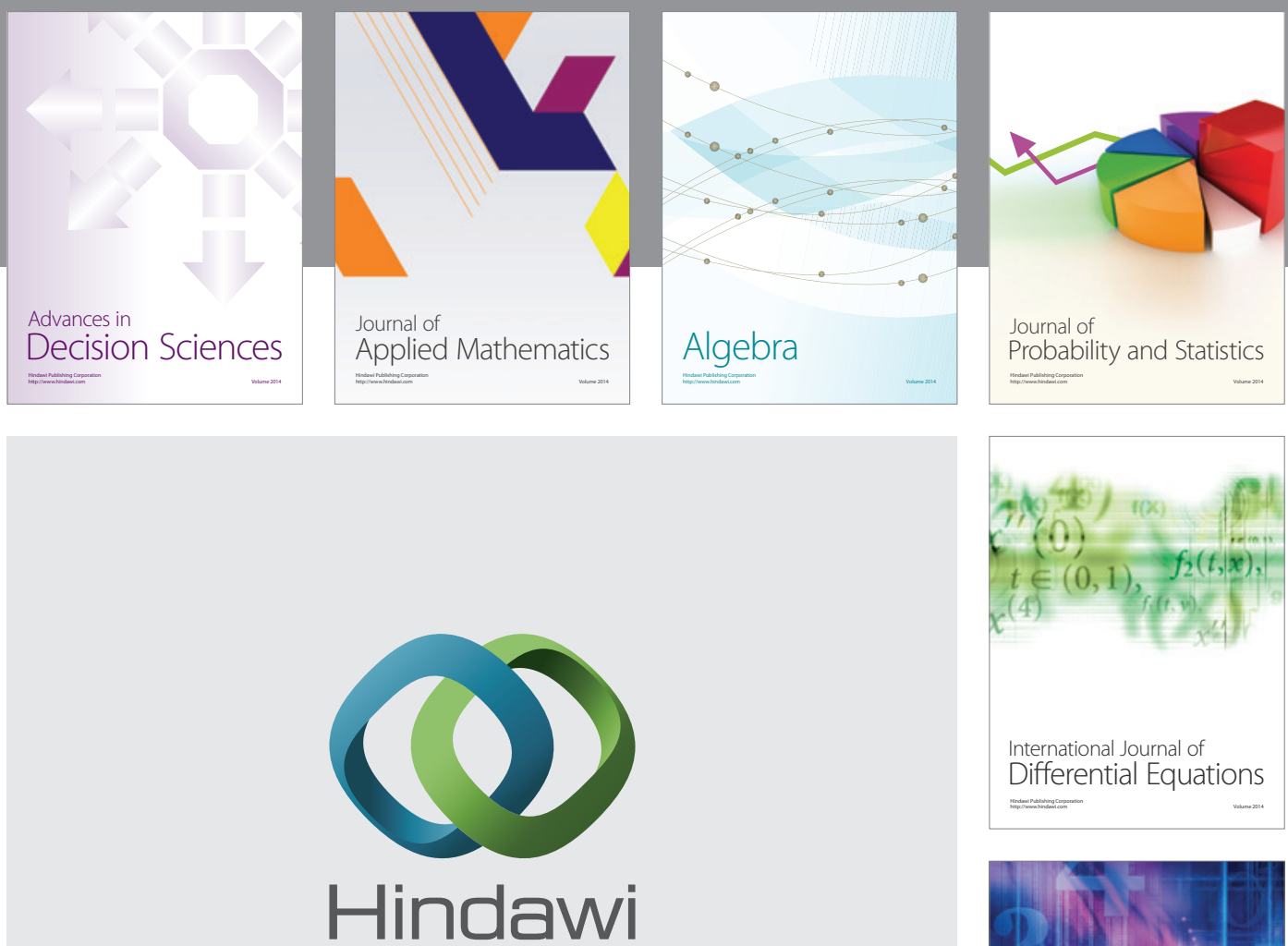

Submit your manuscripts at http://www.hindawi.com
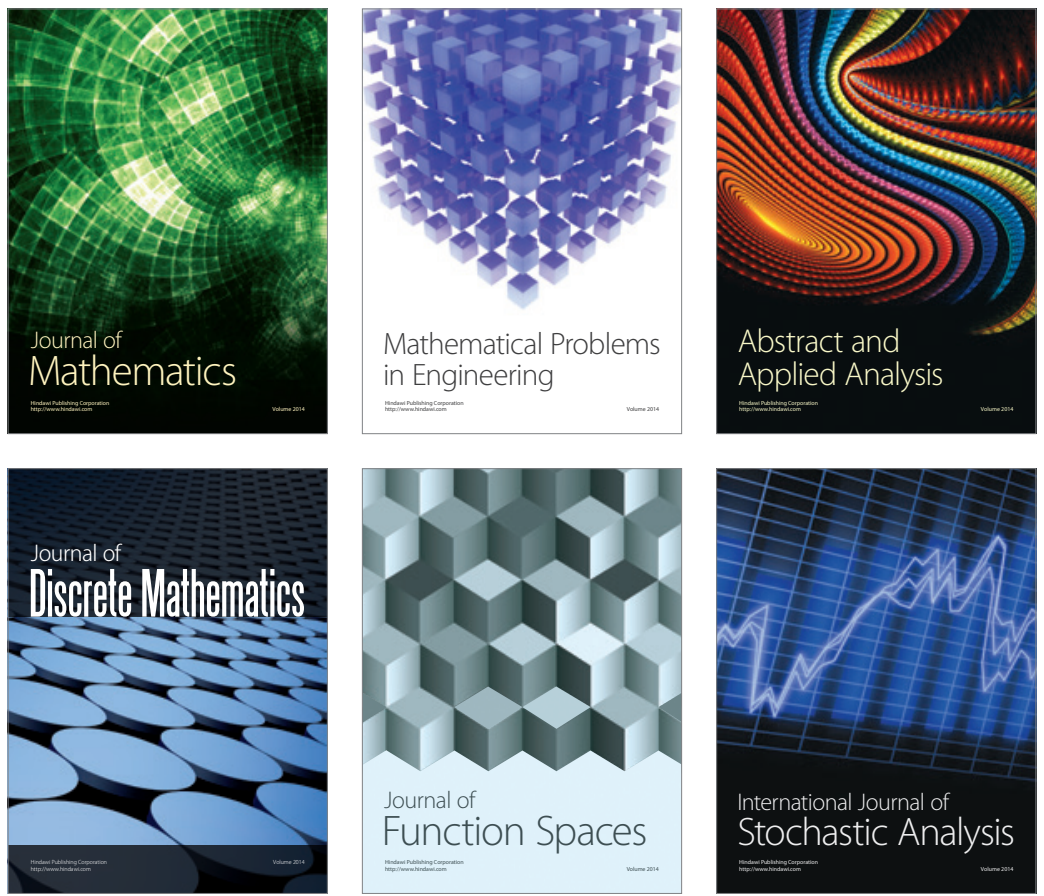

Journal of

Function Spaces

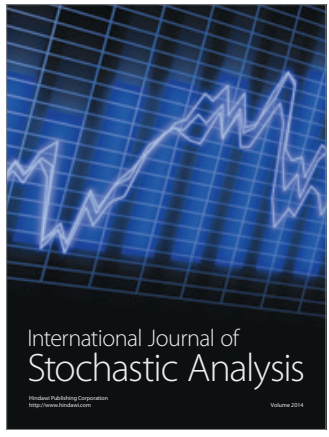

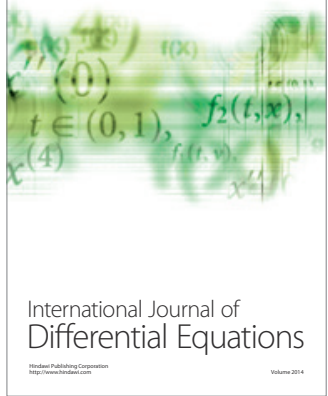
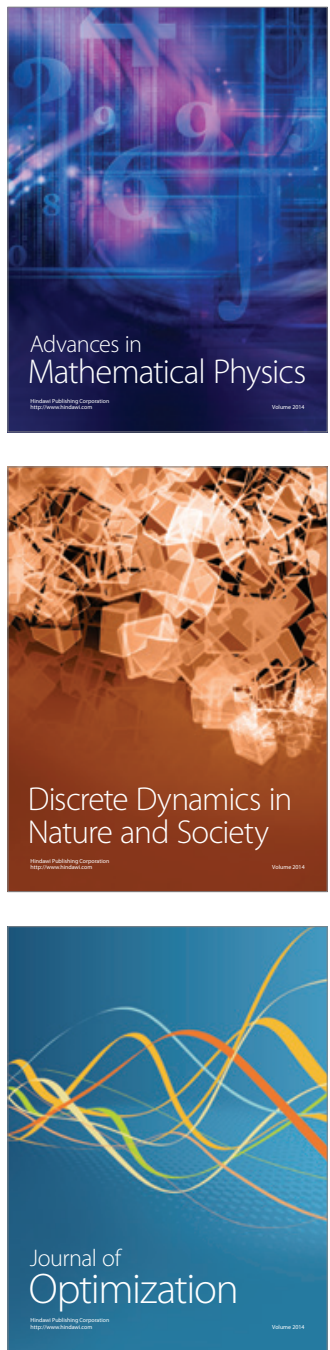